Review Article

\title{
Plant responses to stresses: Role of ascorbate peroxidase in the antioxidant protection
}

Andréia Caverzan ${ }^{1}$, Gisele Passaia ${ }^{1}$, Silvia Barcellos Rosa ${ }^{2}$, Carolina Werner Ribeiro $^{2}$, Fernanda Lazzarotto $^{1}$ and Márcia Margis-Pinheiro ${ }^{1,2^{*}}$

${ }^{1}$ Programa de Pós-Graduação em Genética e Biologia Molecular, Departamento de Genética, Universidade Federal Rio Grande do Sul, Porto Alegre, RS, Brazil.

${ }^{2}$ Programa de Pós-Graduação em Biologia Celular e Molecular, Centro de Biotecnologia, Universidade

Federal Rio Grande do Sul, Porto Alegre, RS, Brazil.

\begin{abstract}
When plants are exposed to stressful environmental conditions, the production of Reactive Oxygen Species (ROS) increases and can cause significant damage to the cells. Antioxidant defenses, which can detoxify ROS, are present in plants. A major hydrogen peroxide detoxifying system in plant cells is the ascorbate-glutathione cycle, in which, ascorbate peroxidase (APX) enzymes play a key role catalyzing the conversion of $\mathrm{H}_{2} \mathrm{O}_{2}$ into $\mathrm{H}_{2} \mathrm{O}$, using ascorbate as a specific electron donor. Different APX isoforms are present in distinct subcellular compartments, such as chloroplasts, mitochondria, peroxisome, and cytosol. The expression of $A P X$ genes is regulated in response to biotic and abiotic stresses as well as during plant development. The APX responses are directly involved in the protection of plant cells against adverse environmental conditions. Furthermore, mutant plants APX genes showed alterations in growth, physiology and antioxidant metabolism revealing those enzymes involvement in the normal plant development.
\end{abstract}

Keywords: ascorbate peroxidase, antioxidant system, reactive oxygen species, abiotic stress, mutant plants.

\section{Plant Responses to Stresses}

The exposure of plants to unfavorable environmental conditions increases the production of reactive oxygen species (ROS) such as, singlet oxygen $\left({ }^{1} \mathrm{O}_{2}\right)$, superoxide $\left(\mathrm{O}_{2}{ }^{-}{ }^{-}\right)$, hydrogen peroxide $\left(\mathrm{H}_{2} \mathrm{O}_{2}\right)$, and hydroxyl radical $\left(\mathrm{OH}^{*}\right)$. The ROS detoxification process in plants is essential for the protection of plant cells and their organelles against the toxic effect of these species (Apel and Hirt, 2004; Mittler, 2002). The differences in subcellular localization and biochemical properties of antioxidant enzymes and the distinct responses in gene expression, in addition to the presence of non-enzymatic mechanisms, result in a versatile and flexible antioxidant system able to control the optimum ROS levels (Vranova et al., 2002). The ROS detoxification systems include enzymatic and non-enzymatic antioxidant components (Scandalios, 2005). Ascorbate (AsA) and glutathione (GSH), non-enzymatic antioxidants are crucial for plant defense against oxidative stress, playing a key role as antioxidant buffers (Foyer and Noctor, 2005; Mittler, 2002). Other non-enzymatic antioxidants involved include

Send corresponce to Marcia Margis-Pinheiro. Departamento de Genética, Universidade Federal do Rio Grande do Sul, Av. Bento Gonçalves 9500, 91501-970 Porto Alegre, RS, Brazil. E-mail: marcia.margis@ufrgs.br. flavonoids, phenolic compounds, alkaloids, tocopherol and carotenoids (Gratão et al., 2005).

Enzymatic antioxidants comprise superoxide dismutase (SOD), ascorbate peroxidase (APX), catalase (CAT), glutathione peroxidase (GPX) and peroxiredoxin (PrxR). These enzymes are present in practically all subcellular compartments. Usually, an organelle has more than one enzyme able to scavenge a single ROS (Mittler, 2002; Mittler et al., 2004; Scandalios, 2005). The main hydrogen peroxide-detoxification system in plant chloroplasts is the ascorbate-glutathione cycle, in which APX is a key enzyme (Asada, 1992). APX utilizes AsA as specific electron donor to reduce $\mathrm{H}_{2} \mathrm{O}_{2}$ to water. The importance of APX and ascorbate-glutathione cycle is not restricted to chloroplasts; it also plays a role in ROS scavenging in cytosol, mitochondria and peroxisomes (Asada, 1992, 1999; Mittler et al., 2004; Noctor and Foyer, 1998; Shigeoka et al., 2002). The ROS-scavenging enzymes in plants have been widely studied and the results have demonstrated that, in response to environmental stress, APX activity generally increases along with other enzymes activities, such as CAT, SOD, and GSH reductase (Shigeoka et al., 2002). Over the past ten years substantial efforts have been made to understand plant antioxidant system mechanisms (Figure1). The in- 


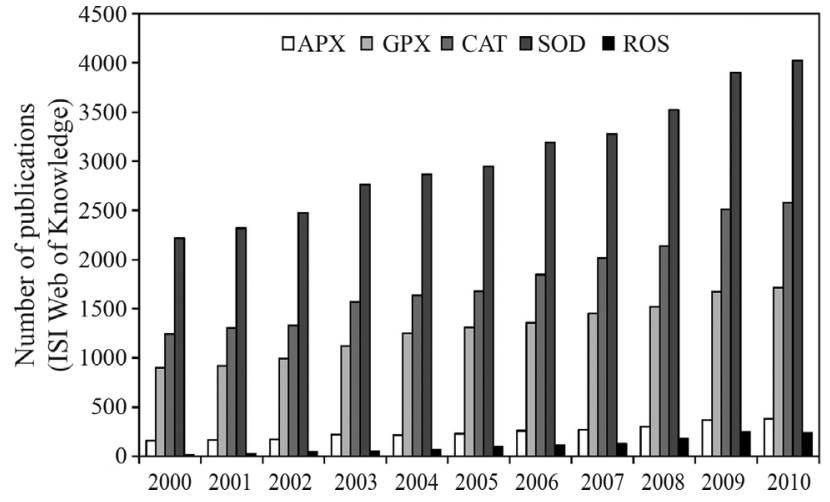

Figure 1 - Number of publication evolution addressing antioxidant enzymes in plants in the last ten years. CAT (catalase), SOD (Superoxide dismutase), GPX (Gluthatione peroxidase) and APX (Ascorbate peroxidase) enzymes, Reactive Oxygen Species (ROS).

creasing number of publications addressing CAT, SOD, GPX and APX enzymes in plants are examples of this tendency, especially APX, which had the number of articles doubled from 158 published in 2000 to 368 in 2010 (ISI Web of Knowledge database). Publications related more specifically to ROS in plants increased 18 times in the same period. The data presented in this study confirm those reported by Azevedo and Azevedo (2006) in which the number of publications addressing antioxidant mechanisms increased after 2000. This shows the relevance of studying these enzymes to further understand the biological processes dealing with oxidative stress responses in plants. The focus of this review is to discuss the main findings related to the APX enzyme at molecular and physiological levels, in different plant species. $A P X$ gene modulation in response to abiotic stress conditions, especially temperature, high light, drought, salinity and heavy metals will also be reviewed.

\section{Ascorbate Peroxidase in Plants}

Ascorbate peroxidase (APX) (EC 1.11.1.11) belongs to the class I heme-peroxidases that is found in higher plants, chlorophytes (Takeda et al., 1998, 2000), red algae (Sano et al., 2001), and members of the protist kingdom (Shigeoka et al., 1980; Wilkinson et al., 2002). APX and other peroxidase sequences from all kingdoms of life are stored in the database Peroxibase (Oliva et al., 2009), which also provides a series of bioinformatics tools useful for analyzing the peroxidases stored sequences.

Genomic and cDNA $A P X$ sequences were obtained from a great variety of plant species, showing that APX are widely distributed in the vegetal kingdom. These enzymes are encoded by small gene families in these organisms (Passardi et al., 2007). The different isoforms are classified according to their subcellular localization. Soluble isoforms are found in cytosol (cAPX), mitochondria (mitAPX) and chloroplast stroma (sAPX), while membrane-bound isoforms are found in microbody (including peroxisome and glyoxisome) (mAPX) and chloroplast thylakoids (tAPX). The presence of organelle-specific targeting peptides and transmembrane domains found in the $\mathrm{N}$ - and C- terminal protein regions determine the final subcellular localization of the isoenzyme (Shigeoka et al., 2002; Teixeira et al., 2004, 2006).

Plant chloroplastic APX (chlAPX) isoenzymes encoding genes are divided into two groups. The first group comprises single genes encoding two isoenzymes through a post-transcriptional alternative splicing regulation. This group includes genes from spinach $(S$. oleracea), tobacco (N. tabacum), pumpkin (Cucurbita $s p$ ) and ice plant (M. crystallium). In the second group, individual genes codify different isoenzymes which are individually regulated. This group includes genes from Arabidopsis, rice, and tomato. The mechanism of alternative splicing in chlAPX has been studied in spinach (Ishikawa and Shigeoka, 2008) and the results showed that alternative splicing is fundamental for controlling the expression of stromal (sAPX) and thylakoid (tAPX) isoenzymes. This regulation occurs in a tissue-dependent manner.

Ascorbate peroxidases have been partially characterized in some plant species. In spinach, the APX family is formed by genes encoding one cytosolic and two chloroplastic (sAPX and tAPX membrane) isoenzymes, one targeted to microbody membrane and an unknown putative cytosol-soluble isoenzyme (Ishikawa et al., 1995, 1996, 1998). In cowpea, four cDNAs were isolated and characterized, corresponding to putative cytosolic, peroxissomal and chloroplastic (thylakoid and stromal) APX isoforms (D'Arcy-Lameta et al., 2006). Six loci encoding $A P X$ were identified in Eucalyptus grandis and their subcellular localizations were indicated by prediction programs. Among the six isoforms, three were putatively identified as cytosolic, one as a putative peroxisomal protein and two predicted to be associated with chloroplasts (Teixeira et al., 2005). In tomato, seven members were identified, three cytosolic, two peroxisomal, and two chloroplastic (Najami et al., 2008). In the model plant Arabidopsis thaliana, the presence of nine $A P X$ genes was described, two choroplastic, one thylakoid-bound and one member whose product is targeted to both chloroplast stroma and mitochondria (Chew et al., 2003); the intracellular localization of an additional member is yet unknown. In addition, three cytosolic and three microsomal proteins were also described (Mittler et al., 2004; Narendra et al., 2006; Panchuk et al., 2002). In another important model plant, rice, the $A P X$ gene family comprises eight members, viz. two cytosolic, two peroxisomal, two chloroplastic (stromal and thylakoid-bound) and two mitochondrial ones (Teixeira et al., 2004, 2006). Recently, a new protein has also been identified as functionally associated with APX in rice, the APX-R (Ascorbate peroxidase-related) (Lazzarotto et al., 2011). Detailed analyses of evolution and structure of $A P X-R$ genes indi- 
cate that these genes correspond to a new class of hemeperoxidases (Lazzarotto et al., 2011).

APX isoenzymes are labile in the absence of AsA. Thus, high level of endogenous AsA is essential to effectively maintain the antioxidant system that protects plants from oxidative damage (Asada, 1992; Shigeoka et al., 2002). Under special conditions in which the concentration of AsA is lower than $20 \mu \mathrm{M}$, the APX activity is quickly lost, this making the chlAPX the least stable isoform. Both cAPX and MAPX have half-inactivation times of around one hour or more, while that for mitAPX and chlAPX is less than 30 seconds (Chen and Asada, 1989; Miyake et al., 1993; Ishikawa et al., 1998; Yoshimura et al., 1998; Leonardis et al., 2000).

\section{APX enzyme Responses Under Abiotic Stress}

The expression of $A P X$ encoding genes is modulated by various environmental stimuli, such as drought and salt stress, high light, high and low temperatures, pathogen attacks, $\mathrm{H}_{2} \mathrm{O}_{2}$ and abscisic acid (Zhang et al., 1997; Yoshimura et al., 2000; Agrawal et al., 2003; Fryer et al., 2003; Menezes-Benavente et al., 2004; Teixeira et al., 2006; Rosa et al., 2010; Bonifacio et al., 2011). Furthermore, the transcriptional expression of $A P X$ genes is tissue and developmental stage dependent (Agrawal et al., 2003; Teixeira et al., 2006).

\section{Salt stress}

Plants are greatly affected by salinity, which causes alteration in nutrient uptake, accumulation of toxic ions, osmotic stress, and oxidative stress (Verslues et al., 2006). Consequently, salinity results in molecular damage, growth arrest, and even cell death (Wang et al., 2008). Salt stress induces the production of ROS, and the response of $A P X$ genes to this condition is tissue and developmental stage regulated. When the response of major antioxidant enzymes transcripts was analyzed for different developmental stages in salt stressed rice, $c A P X$ was up-regulated in 11day-old seedlings, while in 6-week-old plants salt had no significant effect on this gene (Menezes-Benavente et al., 2004). In addition to $A P X$ expression alteration, discrimination on $C A T$ transcript accumulation was also noticed in the basal region of rice leaves under salinity (Yamane et al., 2010). Concerning the APX rice isoforms, induction was observed for the OsAPX1, OsAPX4, OsAPX6 and OsAPX7 genes, whereas cytosolic $O s A P X 2$ gene expression was not altered by salinity (Yamane et al., 2010).

Teixeira et al. (2006) reported that three rice $A P X$ genes, OsAPX2, OsAPX7, and OsAPX8, showed altered transcript levels in response to $\mathrm{NaCl}$ treatment. The expression of OSAPX2 and OSAPX7 was increased, whereas OSAPX8 transcript accumulation was strongly suppressed in plants undergoing salt stress (Teixeira et al., 2006). The transcript level of OSAPX8 was slightly decreased by salin- ity in the basal region of rice leaves (Yamane et al, 2010). On the other hand, OSAPX8 expression in rice roots was enhanced by all $\mathrm{NaCl}$ concentrations tested $(150,200$ and 300 $\mathrm{mM})$, and $O S A P X 7$ expression was down-regulated by 300 $\mathrm{mM} \mathrm{NaCl}$. This discrepancy in regulation for the OSAPX genes might be due to differences in cultivars, organs, plant age and growth conditions (Hong et al., 2007). An increase in rice cytosolic $A P X 2$ gene transcript levels after treatment with salt has previously been shown by our group (Menezes-Benavente et al., 2004; Teixeira et al., 2006). In accordance, transgenic Arabidopsis plants over-expressing cytosolic OsAPXb (OsAPX2) showed higher tolerance to $\mathrm{NaCl}$ than those over-expressing cytosolic OsAPXa (OsAPX1) (Lu et al., 2007). A similar increment in salt stress tolerance was also observed in transgenic tobacco over-expressing the Arabidopsis cAPX gene (Badawi et al., 2004) and also in tobacco plants over-expressing a Solanum lycopersicum thylakoid-bound ascorbate peroxidase gene (StAPX) (Sun et al., 2010b). Transgenic tobacco plants that simultaneously expressed CuZnSOD, APX, and DHAR in chloroplasts presented increased protection against salt induced injury (Lee et al., 2007b). Transgenic tobacco BY-2 cells with 50 and $75 \%$ lower cAPX activity showed higher intracellular content of ROS. On the other hand, the tobacco cells showed a potential enhancement in tolerance to heat and salt stress, perhaps by induction of stress-related gene expression. However, no substantial differences were observed in the activity levels of the other antioxidant enzymes (Ishikawa et al., 2005).

In barley, the transcript level of peroxisomal $A P X$ gene $(H v A P X 1)$ increased significantly under salt stress (Shi et al., 2001). However, Arabidopsis apx3 knockout mutants exposed to normal or stressful conditions did not present disturbed growth or development. In these plants, other antioxidant enzymes possibly compensate the lack of the peroxisomal isoform (Narendra et al., 2006). In contrast, the overexpression of a Populus peroxisomal APX $(P p A P X)$ gene in transgenic tobacco improved salt tolerance at the vegetative stage and plants were more resistant to oxidative damage induced by methyl viologen (MV) and, in addition, the plants had longer roots (Li et al., 2009). Lin and $\mathrm{Pu}(2010)$ studied changes in enzymes involved in ROS scavenging in sweet potato plants tolerant and sensitive to salinity. After exposure to salinity $(450 \mathrm{mM} \mathrm{NaCl})$, APX activity increased in plants at 24 and $48 \mathrm{~h}$, and this response was higher in a salt-stress tolerant genotype than in the salt sensitive ones. The expression of $c A P X, m A P X$ and chlAPX in response to salinity was tissue specific and dependent on stress duration ( $\mathrm{Lin}$ and $\mathrm{Pu}, 2010$ ). Taken together, these studies put in evidence that salt stress causes disturbances in antioxidant gene expression by producing alterations in the transcriptional pattern in several plant species, and that the expression of distinct APX isoform may result in redox homeostasis regulation in each cellular compartment. 


\section{Temperature stress}

Extreme temperatures affect the growth, yield and quality of plant production. ROS levels tend to increase if plants are exposed to stressful conditions such as low or high temperatures (Mittler et al., 2004; Scandalios, 2005). In potato tubers, the transient accumulation of $c A P X$ mRNA after storage at low-temperature was greater than after high-temperature storage, showing that $A P X$ expression was induced in response to low temperature (Kawakami et al., 2002). Likewise, the two rice $c A P X(O s A P X 1$ and $O s A P X 2$ ) genes were induced after rice plants were exposed to low temperatures. Furthermore, OsAPX3, $O s A P X 4, O s A P X 6$ and $O s A P X 7$ were also significantly induced, while $O S A P X 8$ were repressed after $24 \mathrm{~h}$ under low temperature (unpublished data). The sweet potato $c A P X$ gene was highly induced in leaves after exposure to high temperature (Park et al., 2004). In cucumber plants submitted to heat treatment, the activities of cAPX, sAPX and mAPX increased after an initial slight decline during the course of the experiment. The expression of $S A P X$ followed a similar pattern (Song et al., 2005). In response to cold, the expression of a peroxisomal $A P X$ gene increased slightly in Arabidopsis (Zhang et al., 1997).

These results were corroborated in Arabidopsis by overexpressing a putative peroxisomal membrane-bound $A P X$ from barley, resulting in an increased tolerance to higher temperature treatment (Shi et al., 2001). Furthermore, the overexpression of chloroplastic $t A P X$ in tobacco plants improved the tolerance to chilling stress combined with high light intensity (Yabuta et al., 2002). On the other hand, Arabidopsis plants lacking $t A P X$ had enhanced tolerance to heat stress (Miller et al., 2007). Recently, Sato et al. (2011) showed that transgenic rice plants overexpressing a cytosolic $A P X 1$ gene $(O S A P X a)$ which exhibited higher APX activity in spikelets than in wild type (WT) plants, sustained higher levels of APX activity under cold stress, resulting in enhanced cold tolerance at the booting stage.

Plants with enhanced tolerance to multiple environmental stresses were obtained through induced expression of CuZnSod and APX genes. Sod and APX genes were expressed in chloroplasts of potato plants under the control of an oxidative stress inducible promoter - SWPA2. These plants showed enhanced tolerance to $\mathrm{MV}$ and when exposed to $42{ }^{\circ} \mathrm{C}$ for $20 \mathrm{~h}$, the photosynthetic activity of these transgenic plants decreased by only $6 \%$, whereas in nontransformed (NT) plants it decreased by $29 \%$ (Tang et al., 2006). Sweet potato plants expressing both $\mathrm{CuZnSod}$ and $A P X$ in chloroplasts through the inducible promoter also showed higher tolerance to MV-mediated oxidative stress and chilling stress (Lim et al., 2007). The tolerance to high and low temperature stresses was studied in tobacco plants overexpressing a tomato $t A P X$ gene. The overexpression of chloroplastic $A P X$ played a significant role in $\mathrm{H}_{2} \mathrm{O}_{2}$ detoxification and in minimizing photooxidative damage during temperature stress. The transgenic plants showed a higher photochemical efficiency of photosystem II when compared to WT plants under cold and heat stresses (Sun et al., 2010a). These results put in evidence that the manipulation of the antioxidative mechanism in chloroplasts may be applied in the development of plants with increased tolerance to multiple environmental stresses.

\section{High light stress}

Plants exposed to excessive light can suffer photoinhibition, serious damage to the photosynthetic apparatus, and degradation of photosynthetic proteins (DemmigAdams and Adams III, 1992). Light stress can also lead to ROS accumulation and antioxidant enzymes activation (Mittler, 2002). The responses of APX isoenzymes to photooxidative stress were studied in spinach leaves during high light stress. cAPX activity and transcripts increased during high light stress, however protein levels were not altered. The activities of chlAPX isoforms showed a gradual decrease, while the other isoenzymes showed no significant variation in transcript and protein levels, as well as activities (Yoshimura et al., 2000). In wheat, a mutant line showing decreased tAPX activity presented reduced photosynthetic activity and biomass accumulation when growing under high-light intensity, suggesting that tAPX is essential for photosynthesis (Danna et al., 2003). Single mutants of Arabidopsis lacking tAPX or sAPX presented higher levels of $\mathrm{H}_{2} \mathrm{O}_{2}$ and oxidized proteins than WT plants when exposed to high light and MV stresses. The strongest effect of photooxidative stress was observed in plants lacking tAPX, these showing increased $\mathrm{H}_{2} \mathrm{O}_{2}$ accumulation and oxidized proteins (Maruta et al., 2010).

Double mutants deficient in two $A P X$ genes, thylakoid-bound and a cytosolic one (tylapx/apx1), resulted in different signals in Arabidopsis plants, such as late flowering, low protein oxidation during light stress and enhanced accumulation of anthocyanins (Miller et al., 2007). Mutants lacking a functional copy of tAPX, sAPX or both, were characterized in Arabidopsis under photooxidative stress during germination. The stress led to chloroplast bleaching in sapx single-mutant and tapx/sapx doublemutant plants, while the greening process of WT and tapx plants was partially impaired (Kangasjarvi et al., 2008). When mature leaves of tapx/sapx double mutants were submitted to short-term photooxidative stress induced by high light or MV treatment, the plants showed susceptibility (Kangasjarvi et al., 2008). These results indicate that the APXs isoenzymes are indispensable under environmental stresses in different species, especially under light stress conditions.

In Arabidopsis leaves, high light treatment induced the expression of cytosolic $A P X 2$, which has its expression restricted to bundle sheath cells of the vascular tissue (Fryer et al., 2003). In Arabidopsis, APX1 knockout plants showed suppressed growth and development, altered stomatal responses and induction of heat shock proteins 
during light stress. The inactivation of cytosolic APX resulted in the alteration of several transcripts involved in different functions. In transgenic APX1 plants kept under optimal conditions, the transcripts encoding APX enzymes were not elevated. However, during light stress, certain enzymes were induced in knockout-APX1 plants (Pnueli et al., 2003). In another study (Davletova et al., 2005) with APX1-deficient Arabidopsis plants the observation was that the entire chloroplastic $\mathrm{H}_{2} \mathrm{O}_{2}$-scavenging system collapsed, $\mathrm{H}_{2} \mathrm{O}_{2}$ levels increased and protein oxidation occurred in leaves subjected to a moderate light stress, suggesting that the absence of cytosolic APX1 resulted not only in the accumulation of $\mathrm{H}_{2} \mathrm{O}_{2}$ but also in damage to specific proteins in leaf cells. On the other hand, rice plants double silenced for cytosolic APXs up-regulated other peroxidases, making these transgenic plants able to survive under stress, such as salt, heat, high light and MV, similar to NT plants. The antioxidative compensatory mechanism exhibited by the silenced plants was associated with increased expression of Gpx genes. The transcript levels of OsCatA and $O s C a t B$ and the activities of CAT and guaiacol peroxidase (GPOD; type III peroxidases) were also upregulated. In contrast, none of the other isoforms of $O S A P X$ were up-regulated under normal growth conditions. These results suggested that signaling mechanisms triggered in rice could be distinct from those proposed for Arabidopsis (Bonifacio et al., 2011).

\section{Drought stress}

Drought stress in plants leads to severe effects such as reduction in vegetative growth and cell division. As a consequence of drought stress several changes occur inside the cell, including changes in gene expression levels, synthesis of molecular chaperones, and activation of enzymes involved in the production and removal of ROS (Mahajan and Tuteja, 2005). In two cowpea (Vigna unguiculata) cultivars, one drought-tolerant and the other drought-sensitive, APX activity was $60 \%$ higher in tolerant plants cultivated under control conditions. In response to drought stress, a higher increase in transcript levels of cytosolic and peroxisomal $A P X$ genes was observed in the sensitive cultivar (D'Arcy-Lameta et al., 2006). Chloroplastic APX genes expression was stimulated earlier in the tolerant cultivar when submitted to drought stress. These data suggest the capacity of these enzymes to efficiently detoxify ROS at their production site (D'Arcy-Lameta et al., 2006). Relative $A P X$ transcript levels showed distinct changes in two genotypes of wheat exposed to mild water deficit. Cytosolic $A P X 1$ expression levels increased in both genotypes, while cytosolic $A P X 2$ was up-regulated only in the drought-tolerant genotype. The transcript level of thylakoid $A P X$ increased in the drought-tolerant genotype, while stromal $A P X 2$ showed higher expression levels in the drought-sensitive cultivar (Secenji et al., 2010).
$A P X$ gene expression patterns in rice were studied after 15 days of drought stress. In marked contrast with the experiments with wheat, thylakoid $A P X(O s A P X 8)$ expression was down-regulated in this condition, while the OsAPX1, OsAPX2, OsAPX5, OsAPX6 and OsAPX7 genes were up-regulated. The peroxisomal OsAPX3 gene was not affected, while $O S A P X 4$ was slightly but significantly down-regulated by this treatment (Rosa et al., 2010). This discrepancy could be due to distinct responses of $A P X$ genes in different species and to different magnitudes of stress. In Arabidopsis, APX1 protein and mRNA accumulated during combination of heat and drought stress. A cytosolic $A P X 1$-deficient mutant accumulated more $\mathrm{H}_{2} \mathrm{O}_{2}$ and was more sensitive to stress combination than WT plants when exposed to heat and drought stress combined. In contrast, plants deficient in thylakoid APX were not more sensitive to this stress combination than APX1-deficient mutant or WT plants. The cytosolic $A P X 1$ gene may thus play a key role in the acclimation of plants to combined stress such drought and heat (Koussevitzky et al., 2008). Indeed, when the overexpression of cytosolic $A P X$ was studied in tobacco chloroplasts, its overexpression protected the plant from several oxidative stresses, including drought and polyethylene glycol-induced stress (Badawi et al., 2004). Plants overexpressing other antioxidant enzymes in different species showed increased tolerance to various stresses, including drought resistance. The overexpression of a Populus peroxisomal ascorbate peroxidase $(P p A P X)$ gene in transgenic tobacco improved drought resistance in these plants (Li et al., 2009). The overexpression of tomato (Solanum lycopersicum) thylakoid-bound APX (StAPX) gene in tobacco plants enhanced the tolerance of these plants to salt and osmotic stress (Sun et al., 2010b).

\section{Heavy metals}

The contamination of soils with heavy metals is a serious environmental problem that limits crop production. Exposure at higher concentrations of heavy metals can increase the production of ROS and change antioxidant response (Gratão et al., 2005). Exposure of pea (Pisum sativum L.) plants to cadmium changed enzymatic and non-enzymatic antioxidant defenses, however, APX activity or accumulation of its transcripts were not significantly different (Romero-Puertas et al., 2007). However, it was observed that in coffee cells, the activity of APX was increased at the lower cadmium concentration. On the other hand, APX activity was not detectable in cells submitted to the higher cadmium concentration after $24 \mathrm{~h}$ of treatment (Gomes-Junior et al., 2006b).

An increase in APX activity was also observed in response to other heavy metals such as aluminum (Sharma and Dubey, 2007). In rice, the transcript levels of all $O S A P X$ genes, except OsAPX6, were significantly increased after eight hours of $20 \mathrm{ppm}$ aluminum exposure (Rosa et al., 2010). In pea plants, $c A P X$ expression increased in the 
shoots under aluminum treatment, but APX activity presented a significant decline at $10 \mu \mathrm{M}$ aluminum in roots and shoots after 24 and $48 \mathrm{~h}$ of stress; at $50 \mu \mathrm{M}$ aluminum treatment, however, APX activity did not show any significant changes (Panda and Matsumoto, 2010). Transgenic rice plants double silenced for $A P X 1$ and $A P X 2$ (APX1/2s plants) exhibited normal development and enhanced tolerance to a toxic concentration of aluminum (Rosa et al., 2010). In bean plants, the expression of cytosolic APX was induced both at mRNA and protein levels in leaves of de-rooted plants in response to iron overload. Likewise, transgenic tobacco plants with suppressed cytosolic APX levels were more sensitive to iron application than WT plants (Pekker et al., 2002). In coffee cells treated with nickel showed a rapid increase in APX activity, although the activity trends were slightly different between the two nickel concentrations tested $(0.05 \mathrm{mM}$ and $0.5 \mathrm{mM})$ (Gomes-Junior et al., 2006a). Transgenic tall fescue plants expressing the CuZnSOD and APX genes in chloroplasts were submitted to copper, cadmium or arsenic treatment. Of the metals tested, copper and cadmium increased SOD and APX activities in control and transgenic plants, with a higher increase observed in transgenic plants. In contrast, in leaves exposed to arsenic, both enzymes exhibited less activity when compared to other treatments and no significant differences were observed between control and transgenic plants (Lee et al., 2007a). These results emphasize the important role of APX and other antioxidant enzymes in $\mathrm{H}_{2} \mathrm{O}_{2}$ scavenging under toxic metals levels in the soil.

\section{Conclusions}

Ascorbate peroxidase is a key enzyme regulating ROS levels acting in different subcellular compartments (Figure 2). The expression of $A P X$ encoding genes is differentially modulated by several abiotic stresses in different plant species. All the data collected so far firmly indicate that APX isoforms play important and direct roles as protective elements against adverse environmental conditions. The diverse effects of knockdown or knockout of different $A P X$ genes on the plant growth, physiology and antioxidant metabolism indicate that APX may also regulate redox signaling pathways involved in plant development. These re-

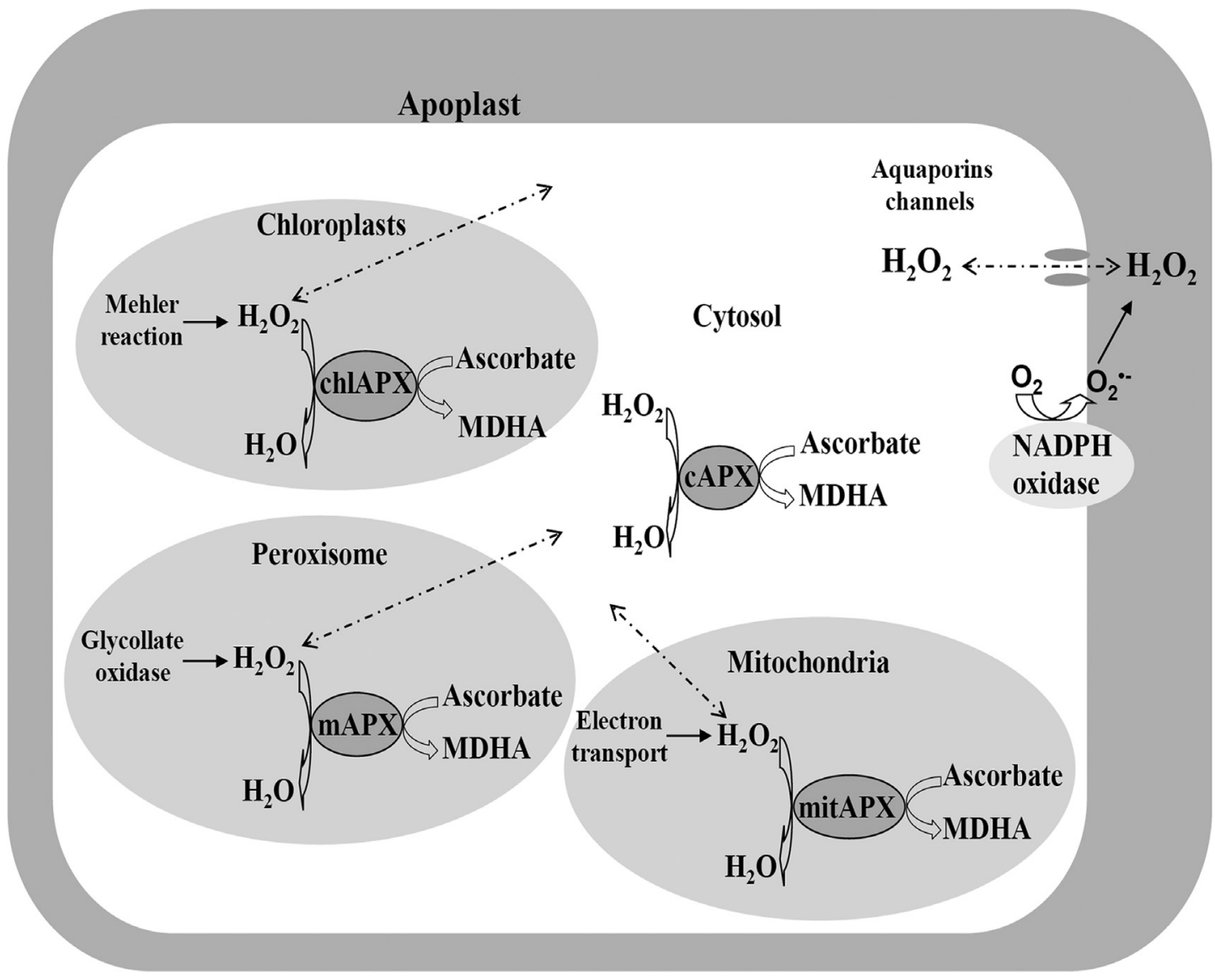

Figure 2 - APX enzymes and the elimination of ROS excess in different subcellular compartments. $\mathrm{H}_{2} \mathrm{O}_{2}$ is generated in normal metabolism via the Mehler reaction in chloroplasts, electron transport in mitochondria and photorespiration in peroxisomes. Abiotic and biotic stresses enhance $\mathrm{H}_{2} \mathrm{O}_{2}$ and chlAPX, mAPX, cAPX and mitAPX enzymes which can eliminate ROS excess in different subcellular compartments. The plasma membrane-NADPH oxidases also generate $\mathrm{H}_{2} \mathrm{O}_{2}$, which can cross membranes through aquaporin channels. Superoxide $\left(\mathrm{O}_{2}{ }^{--}\right)$, hydrogen peroxide $\left(\mathrm{H}_{2} \mathrm{O}_{2}\right)$, monodehydroascorbate (MDHA). 
sults emphasize the importance and complexity of the interactions of APX with other antioxidants in fine tuning the vegetal antioxidant metabolism.

\section{Acknowledgments}

The authors are grateful to Conselho Nacional de Desenvolvimento Científico e Tecnológico (CNPq) and Coordenação de Aperfeiçoamento de Pessoal de Nível Superior (CAPES) for financial support.

\section{References}

Agrawal GK, Jwa NS, Iwahashi H and Rakwal R (2003) Importance of ascorbate peroxidases OsAPX1 and OsAPX2 in the rice pathogen response pathways and growth and reproduction revealed by their transcriptional profiling. Gene 322:93-103.

Apel K and Hirt H (2004) Reactive oxygen species: Metabolism, oxidative stress, and signal transduction. Annu Rev Plant Biol 55:373-399.

Asada K (1992) Ascorbate peroxidase - A hydrogen peroxide-scavenging enzyme in plants. Physiol Plantarum 85:235-241.

Asada K (1999) The water cycle in chloroplasts: Scavenging of active oxygens and dissipation of excess photons. Annu Rev Plant Physiol Plant Mol Biol 50:601-639.

Azevedo JA and Azevedo RA (2006) Heavy metals and oxidative stress: Where do we go from here? Commun Biometry Crop Sci 1:135-138.

Badawi GH, Kawano N, Yamauchi Y, Shimada E, Sasaki R, Kubo A and Tanaka K (2004) Over-expression of ascorbate peroxidase in tobacco chloroplasts enhances the tolerance to salt stress and water deficit. Physiol Plant 121:231-238.

Bonifacio A, Martins MO, Ribeiro CW, Fontenele AV, Carvalho FE, Margis-Pinheiro M and Silveira JA (2011) Role of peroxidases in the compensation of cytosolic ascorbate peroxidase knockdown in rice plants under abiotic stress. Plant Cell Environ 34:1705-1722.

Chen GX and Asada K (1989) Ascorbate peroxidase in tea leaves: Occurrence of two isozymes and the differences in their enzymatic and molecular properties. Plant Cell Physiol 30:897-998.

Chew O, Whelan J and Millar AH (2003) Molecular definition of the ascorbate-glutathione cycle in Arabidopsis mitochondria reveals dual targeting of antioxidant defenses in plants. J Biol Chem 278:46869-46877.

D'Arcy-Lameta A, Ferrari-Iliou R, Contour-Ansel D, Pham-Thi AT and Zuily-Fodil Y (2006) Isolation and characterization of four ascorbate peroxidase cDNAs responsive to water deficit in cowpea leaves. Ann Bot 97:133-140.

Danna CH, Bartoli CG, Sacco F, Ingala LR, Santa-Maria GE, Guiamet JJ and Ugalde RA (2003) Thylakoid-bound ascorbate peroxidase mutant exhibits impaired electron transport and photosynthetic activity. Plant Physiol 132:2116-2125.

Davletova S, Rizhsky L, Liang H, Shengqiang Z, Oliver DJ, Coutu J, Shulaev V, Schlauch K and Mittler R (2005) Cytosolic ascorbate peroxidase 1 is a central component of the reactive oxygen gene network of Arabidopsis. Plant Cell $17: 268-281$.
Demmig-Adams B and Adams WW III (1992) Photoprotection and other responses of plants to high light stress. Annu Rev Plant Physiol and Plant Mol Biol 43:599-626.

Foyer CH and Noctor G (2005) Redox homeostasis and antioxidant signaling: A metabolic interface between stress perception and physiological responses. Plant Cell 17:1866-1875.

Fryer MJ, Ball L, Oxborough K, Karpinski S, Mullineaux PM and Baker NR (2003) Control of Ascorbate Peroxidase 2 expression by hydrogen peroxide and leaf water status during excess light stress reveals a functional organisation of Arabidopsis leaves. Plant J 33:691-705.

Gomes-Junior RA, Moldes CA, Delite FS, Gratão PL, Mazzafera P, Lea PJ and Azevedo RA (2006a) Nickel elicits a fast antioxidant response in Coffea arabica cells. Plant Physiol Biochem 44:420-429.

Gomes-Junior RA, Moldes CA, Delite FS, Pompeu GB, Gratão PL, Mazzafera P, Lea PJ and Azevedo RA (2006b) Antioxidant metabolism of coffee cell suspension cultures in response to cadmium. Chemosphere 65:1330-1337.

Gratão PL, Polle A, Lea PJ and Azevedo RA (2005) Making the life of heavy metal-stressed plants a little easier. Funct Plant Biol 32:481-494.

Hong CY, Hsu YT, Tsai YC and Kao CH (2007) Expression of ASCORBATE PEROXIDASE 8 in roots of rice (Oryza sativa L.) seedlings in response to $\mathrm{NaCl}$. J Exp Bot 58:3273-3283.

Ishikawa T and Shigeoka S (2008) Recent advances in ascorbate biosynthesis and the physiological significance of ascorbate peroxidase in photosynthesizing organisms. Biosci Biotechnol Biochem 72:1143-1154.

Ishikawa T, Sakai K, Takeda T and Shigeoka S (1995) Cloning and expression of cDNA encoding a new type of ascorbate peroxidase from spinach. FEBS Lett 367:28-32.

Ishikawa T, Sakai K, Yoshimura K, Takeda T and Shigeoka S (1996) cDNAs encoding spinach stromal and thylakoidbound ascorbate peroxidase, differing in the presence or absence of their 3'-coding regions. FEBS Lett 384:289-293.

Ishikawa T, Yoshimura K, Sakai K, Tamoi M, Takeda T and Shigeoka S (1998) Molecular characterization and physiological role of a glyoxysome-bound ascorbate peroxidase from spinach. Plant Cell Physiol 39:23-34.

Ishikawa T, Morimoto Y, Madhusudhan R, Sawa Y, Shibata H, Yabuta Y, Nishizawa A and Shigeoka S (2005) Acclimation to diverse environmental stresses caused by a suppression of cytosolic ascorbate peroxidase in tobacco BY-2 cells. Plant Cell Physiol 46:1264-1271.

Kangasjarvi S, Lepisto A, Hannikainen K, Piippo M, Luomala EM, Aro EM and Rintamaki E (2008) Diverse roles for chloroplast stromal and thylakoid-bound ascorbate peroxidases in plant stress responses. Biochem J 412:275-285.

Kawakami S, Matsumoto Y, Matsunaga A, Mayama S and Mizuno M (2002) Molecular cloning of ascorbate peroxidase in potato tubers and its response during storage at low temperature. Plant Sci 163:829-836.

Koussevitzky S, Suzuki N, Huntington S, Armijo L, Sha W, Cortes D, Shulaev V and Mittler R (2008) Ascorbate peroxidase 1 plays a key role in the response of Arabidopsis thaliana to stress combination. J Biol Chem 283:3419734203.

Lazzarotto F, Teixeira FK, Rosa SB, Dunand C, Fernandes CL, de Vasconcelos Fontenele A, Silveira JA, Verli H, Margis R 
and Margis-Pinheiro M (2011) Ascorbate peroxidaserelated $(A P x-R)$ is a new heme-containing protein functionally associated with ascorbate peroxidase but evolutionarily divergent. New Phytol 191:234-250.

Lee SH, Ahsan N, Lee KW, Kim DH, Lee DG, Kwak SS, Kwon SY, Kim TH and Lee BH (2007a) Simultaneous overexpression of both $\mathrm{CuZn}$ superoxide dismutase and ascorbate peroxidase in transgenic tall fescue plants confers increased tolerance to a wide range of abiotic stresses. J Plant Physiol 164:1626-1638.

Lee YP, Kim SH, Bang JW, Lee HS, Kwak SS and Kwon SY (2007b) Enhanced tolerance to oxidative stress in transgenic tobacco plants expressing three antioxidant enzymes in chloroplasts. Plant Cell Rep 26:591-598.

Leonardis S, Dipierro N and Dipierro S (2000) Purification and characterization of an ascorbate peroxidase from potato tuber mitochondria. Plant Physiol Biochem 38:773-779.

Li Y-J, Hai R-L, Du X-H, Jiang X-N and Lu H (2009) Overexpression of a Populus peroxisomal ascorbate peroxidase (PpAPX) gene in tobacco plants enhances stress tolerance. Plant Breed 128:404-410.

Lim S, Kim Y-H, Kim S-H, Kwon S-Y, Lee H-S, Kim J-S, Cho K-Y, Paek K-Y and Kwak S-S (2007) Enhanced tolerance of transgenic sweetpotato plants that express both $\mathrm{CuZnSOD}$ and APX in chloroplasts to methyl viologen-mediated oxidative stress and chilling. Mol Breed 19:227-239.

Lin KH and Pu SF (2010) Tissue- and genotype-specific ascorbate peroxidase expression in sweet potato in response to salt stress. Biol Plantarum 54:664-670.

Lu Z, Liu D and Liu S (2007) Two rice cytosolic ascorbate peroxidases differentially improve salt tolerance in transgenic Arabidopsis. Plant Cell Rep 26:1909-1917.

Mahajan S and Tuteja N (2005) Cold, salinity and drought stresses: An overview. Arch Biochem Biophys 444:139-158.

Maruta T, Tanouchi A, Tamoi M, Yabuta Y, Yoshimura K, Ishikawa T and Shigeoka S (2010) Arabidopsis chloroplastic ascorbate peroxidase isoenzymes play a dual role in photoprotection and gene regulation under photooxidative stress. Plant Cell Physiol 51:190-200.

Menezes-Benavente L, Teixeira FK, Kamei CLA and MargisPinheiro M (2004) Salt stress induces altered expression of genes encoding antioxidant enzymes in seedlings of a Brazilian indica rice (Oryza sativa L.) Plant Sci 166:323-331.

Miller G, Suzuki N, Rizhsky L, Hegie A, Koussevitzky S and Mittler R (2007) Double mutants deficient in cytosolic and thylakoid ascorbate peroxidase reveal a complex mode of interaction between reactive oxygen species, plant development, and response to abiotic stresses. Plant Physiol 144:1777-1785.

Mittler R (2002) Oxidative stress, antioxidants and stress tolerance. Trends Plant Sci 7:405-410.

Mittler R, Vanderauwera S, Gollery M and Van Breusegem F (2004) Reactive oxygen gene network of plants. Trends Plant Sci 9:490-498.

Miyake C, Cao WH and Asada K (1993) Purification and molecular properties of thylakoid-bound ascorbate peroxidase in spinhach chloroplasts. Plant Cell Physiol 34:881-889.

Najami N, Janda T, Barriah W, Kayam G, Tal M, Guy M and Volokita M (2008) Ascorbate peroxidase gene family in tomato: Its identification and characterization. Mol Genet Genomics 279:171-182.
Narendra S, Venkataramani S, Shen G, Wang J, Pasapula V, Lin Y, Kornyeyev D, Holaday AS and Zhang H (2006) The Arabidopsis ascorbate peroxidase 3 is a peroxisomal membrane-bound antioxidant enzyme and is dispensable for Arabidopsis growth and development. J Exp Bot 57:30333042.

Noctor G and Foyer CH (1998) Ascorbate glutathione: Keeping active oxygen under control. Annu Rev Plant Physiol Plant Mol Biol 49:249-279.

Oliva M, Theiler G, Zamocky M, Koua D, Margis-Pinheiro M, Passardi F and Dunand C (2009) PeroxiBase: A powerful tool to collect and analyse peroxidase sequences from Viridiplantae. J Exp Bot 60:453-459.

Panchuk II, Volkov RA and Schöffl F (2002) Heat stress- and heat shock transcription factor-dependent expression and activity of ascorbate peroxidase in Arabidopsis. Plant Physiol 129:838-853

Panda SK and Matsumoto H (2010) Changes in antioxidant gene expression and induction of oxidative stress in pea (Pisum sativum $\mathrm{L}$.) under $\mathrm{Al}$ stress. Biometals 23:753-762.

Park SY, Ryu SH, Jang IC, Kwon SY, Kim JG and Kwak SS (2004) Molecular cloning of a cytosolic ascorbate peroxidase cDNA from cell cultures of sweet potato and its expression in response to stress. Mol Genet Genomics 271:339346.

Passardi F, Bakalovic N, Teixeira FK, Margis-Pinheiro M, Penel $\mathrm{C}$ and Dunand C (2007) Prokaryotic origins of the nonanimal peroxidase superfamily and organelle-mediated transmission to eukaryotes. Genomics 89:567-579.

Pekker I, Tel-Or E and Mittler R (2002) Reactive oxygen intermediates and glutathione regulate the expression of cytosolic ascorbate peroxidase during iron-mediated oxidative stress in bean. Plant Mol Biol 49:429-438.

Pnueli L, Liang H, Rozenberg M and Mittler R (2003) Growth suppression, altered stomatal responses, and augmented induction of heat shock proteins in cytosolic ascorbate peroxidase (Apx1)-deficient Arabidopsis plants. Plant J 34:187203.

Romero-Puertas MC, Corpas FJ, Rodríguez-Serrano M, Gómez M, Río LAd and Sandalio LM (2007) Differential expression and regulation of antioxidative enzymes by cadmium in pea plants. J Plant Physiol 164:1346-1357.

Rosa SB, Caverzan A, Teixeira FK, Lazzarotto F, Silveira JA, Ferreira-Silva SL, Abreu-Neto J, Margis R and MargisPinheiro M (2010) Cytosolic APx knockdown indicates an ambiguous redox responses in rice. Phytochemistry 71:548-558

Sano S, Ueda M, Kitajima S, Takeda T, Shigeoka S, Kurano N, Miyachi S, Miyake C and Yokota A (2001) Characterization of ascorbate peroxidases from unicellular red alga Galdieria partita. Plant Cell Physiol 42:433-440.

Sato Y, Masuta Y, Saito K, Murayama S and Ozawa K (2011) Enhanced chilling tolerance at the booting stage in rice by transgenic overexpression of the ascorbate peroxidase gene, OsAPXa. Plant Cell Rep 30:299-406.

Scandalios JG (2005) Oxidative stress: Molecular perception and transduction of signals triggering antioxidant gene defenses. Braz J Med Biol Res 38:995-1014.

Secenji M, Hideg E, Bebes A and Gyorgyey J (2010) Transcriptional differences in gene families of the ascorbate-gluta- 
thione cycle in wheat during mild water deficit. Plant Cell Rep 29:37-50.

Sharma P and Dubey RS (2007) Involvement of oxidative stress and role of antioxidative defense system in growing rice seedlings exposed to toxic concentrations of aluminum. Plant Cell Rep 26:2027-2038.

Shi WM, Muramoto Y, Ueda A and Takabe T (2001) Cloning of peroxisomal ascorbate peroxidase gene from barley and enhanced thermotolerance by overexpressing in Arabidopsis thaliana. Gene 273:23-27.

Shigeoka S, Ishikawa T, Tamoi M, Miyagawa Y, Takeda T, Yabuta Y and Yoshimura K (2002) Regulation and function of ascorbate peroxidase isoenzymes. J Exp Bot 53:13051319 .

Shigeoka S, Nakano Y and Kitaoka S (1980) Metabolism of hydrogen peroxide in Euglena gracilis Z by L-ascorbic acid peroxidase. Biochem J 186:377-380.

Song XS, Hu WH, Mao WH, Ogweno JO, Zhou YH and Yu JQ (2005) Response of ascorbate peroxidase isoenzymes and ascorbate regeneration system to abiotic stresses in Cucumis sativus L. Plant Physiol Biochem 43:1082-1088.

Sun W-H, Duan M, Li F, Shu D-F, Yang S and Meng Q-W (2010a) Overexpression of tomato tAPX gene in tobacco improves tolerance to high or low temperature stress. Biol Plantarum 54:614-620.

Sun WH, Duan M, Shu DF, Yang S and Meng QW (2010b) Over-expression of StAPX in tobacco improves seed germination and increases early seedling tolerance to salinity and osmotic stresses. Plant Cell Rep 29:917-926.

Takeda T, Yoshimura K, Ishikawa T and Shigeoka S (1998) Purification and characterization of ascorbate peroxidase in Chlorella vulgaris. Biochimie 80:295-301.

Takeda T, Yoshimura K, Yoshii M, Kanahoshi H, Miyasaka H and Shigeoka S (2000) Molecular characterization and physiological role of ascorbate peroxidase from halotolerant Chlamydomonas sp. W80 strain. Arch Biochem Biophys 376:82-90.

Tang L, Kwon SY, Kim SH, Kim JS, Choi JS, Cho KY, Sung CK, Kwak SS and Lee HS (2006) Enhanced tolerance of transgenic potato plants expressing both superoxide dismutase and ascorbate peroxidase in chloroplasts against oxidative stress and high temperature. Plant Cell Rep 25:1380-1386.

Teixeira FK, Menezes-Benavente L, Margis R and MargisPinheiro M (2004) Analysis of the molecular evolutionary history of the ascorbate peroxidase gene family: Inferences from the rice genome. J Mol Evol 59:761-770.

Teixeira FK, Menezes-Benavente L, Galvão VC and MargisPinheiro M (2005) Multigene families encode the major en- zymes of antioxidant metabolism in Eucalyptus grandis L. Genet Mol Biol 28:529-538.

Teixeira FK, Menezes-Benavente L, Galvão VC, Margis R and Margis-Pinheiro M (2006) Rice ascorbate peroxidase gene family encodes functionally diverse isoforms localized in different subcellular compartments. Planta 224:300-314.

Verslues PE, Agarwal M, Katiyar-Agarwal S, Zhu J and Zhu JK (2006) Methods and concepts in quantifying resistance to drought, salt and freezing, abiotic stresses that affect plant water status. Plant J 45:523-539.

Vranova E, Inze D and Van Breusegem F (2002) Signal transduction during oxidative stress. J Exp Bot 53:1227-1236.

Wang R, Chen S, Zhou X, Shen X, Deng L, Zhu H, Shao J, Shi Y, Dai S, Fritz E, Huttermann A and Polle A (2008) Ionic homeostasis and reactive oxygen species control in leaves and xylem sap of two poplars subjected to $\mathrm{NaCl}$ stress. Tree Physiol 28:947-957.

Wilkinson SR, Obado SO, Mauricio IL and Kelly JM (2002) Trypanosoma cruzi expresses a plant-like ascorbate-dependent hemoperoxidase localized to the endoplasmic reticulum. Proc Natl Acad Sci USA 99:13453-13458.

Yabuta Y, Motoki T, Yoshimura K, Takeda T, Ishikawa T and Shigeoka S (2002) Thylakoid membrane-bound ascorbate peroxidase is a limiting factor of antioxidative systems under photo-oxidative stress. Plant J 32:915-925.

Yamane K, Mitsuya S, Taniguchi M and Miyake H (2010) Transcription profiles of genes encoding catalase an ascorbate peroxidase in rice leaf tissues under salinity. Plant Prod Sci 13:164-168.

Yoshimura K, Ishikawa T, Nakamura Y, Tamoi M, Takeda T, Tada T, Nishimura K and Shigeoka S (1998) Comparative study on recombinant chloroplastic and cytosolic ascorbate peroxidase isozymes of spinach. Arch Biochem Biophys 353:55-63.

Yoshimura K, Yabuta Y, Ishikawa T and Shigeoka S (2000) Expression of spinach ascorbate peroxidase isoenzymes in response to oxidative stresses. Plant Physiol 123:223-234.

Zhang H, Wang J, Nickel U, Allen RD and Goodman HM (1997) Cloning and expression of an Arabidopsis gene encoding a putative peroxisomal ascorbate peroxidase. Plant Mol Biol 34:967-971.

\section{Internet Resources}

Oliva et al., (2009) Peroxibase, http://peroxibase.isb-sib.ch (May $30,2011)$.

License information: This is an open-access article distributed under the terms of the Creative Commons Attribution License, which permits unrestricted use, distribution, and reproduction in any medium, provided the original work is properly cited. 